BMJ Surgery, Interventions, \& Health Technologies

\section{COVIDTrach: a prospective cohort study of mechanically ventilated patients with COVID-19 undergoing tracheostomy in the UK}

To cite: . COVIDTrach: a prospective cohort study of mechanically ventilated patients with COVID-19 undergoing tracheostomy in the UK. BMJ Surg Interv Health Technologies 2021;3:e000077. doi:10.1136/ bmjsit-2020-000077

- Additional supplemental material is published online only. To view, please visit the journal online (http://dx.doi.org/10. 1136/bmjsit-2020-000077).

Received 19 December 2020 Accepted 09 June 2021

Check for updates

(C) Author(s) (or their employer(s)) 2021. Re-use permitted under CC BY-NC. No commercial re-use. See rights and permissions. Published by BMJ.

Division of Surgery \& Interventional Science, University College London, London, UK

Correspondence to Nick JI Hamilton; nick.hamilton@ucl.ac.uk

\section{ABSTRACT}

Objectives COVIDTrach is a UK multicentre prospective cohort study project that aims to evaluate the outcomes of tracheostomy in patients with COVID-19 receiving mechanical ventilation and record the incidence of SARS-CoV-2 infection among healthcare workers involved in the procedure.

Design Data on patient demographic, clinical history and outcomes were entered prospectively and updated over time via an online database (REDCap). Clinical variables were compared with outcomes, with logistic regression used to develop a model for mortality. Participants recorded whether any operators tested positive for SARSCoV-2 within 2 weeks of the procedure.

Setting UK National Health Service departments involved in treating patients with COVID-19 receiving mechanical ventilation.

Participants The cohort comprised 1605 tracheostomy cases from 126 UK hospitals collected between 6 April and 26 August 2020.

Main outcome measures Mortality following tracheostomy, successful wean from mechanical ventilation and length of time from tracheostomy to wean, discharge from hospital, complications from tracheostomy, reported SARS-CoV-2 infection among operators.

Results The median time from intubation to tracheostomy was 15 days (IQR 11, 21). 285 (18\%) patients died following the procedure. $1229(93 \%)$ of the survivors had been successfully weaned from mechanical ventilation at censoring and 1049 (81\%) had been discharged from hospital. Age, inspired oxygen concentration, positive end-expiratory pressure setting, fever, number of days of ventilation before tracheostomy, $\mathrm{C}$ reactive protein and the use of anticoagulation and inotropic support independently predicted mortality. Six reports were received of operators testing positive for SARSCoV-2 within 2 weeks of the procedure.

Conclusions Tracheostomy appears to be safe in mechanically ventilated patients with COVID-19 and to operators performing the procedure and we identified clinical parameters that are predictive of mortality.

Trial registration number The study is registered with ClinicalTrials.Gov (NCT04572438).

\section{INTRODUCTION}

Data indicate that 5\%-12\% of patients with SARS-CoV-2 infection develop a severe illness requiring critical care, of whom $72 \%-81 \%$

\section{Key messages}

What is already known about this subject?

- In the prepandemic setting, tracheostomy is deployed routinely in intensive care patients who required prolonged mechanical ventilation.

- A number of single-centre studies have reported successful outcomes in terms or weaning from ventilation following tracheostomy in patients with COVID-19.

- High rates of infection with SARS-CoV-2 among operators performing the tracheostomy have not been reported in the small number of series that examine this question.

\section{What are the new findings?}

- We provide outcome data on a national cohort of patients with COVID-19 undergoing tracheostomy and show mortality is not higher than expected.

- Age, days of mechanical ventilation preprocedure, inspired oxygen concentration and positive endexpiratory pressure setting at the time of tracheostomy and upward trending $C$ reactive protein are independently associated with mortality.

- Out of the 1605 tracheostomy cases reviewed, only six cases of SARS-CoV-2 infection among operators were reported.

How might these results affect future research or surgical practice?

- The data support the use of tracheostomy among patients with COVID-19 requiring prolonged mechanical ventilation.

- The clinical parameters highlighted in this report should be considered in the clinical decision-making of when to proceed with tracheostomy in ventilated patients with COVID-19.

require invasive mechanical ventilation. ${ }^{1-5}$ Standard UK intensive care practice is to consider tracheostomy after 7-10 days of invasive mechanical ventilation to aid weaning, facilitate comfort and minimise complications relating to the prolonged presence of an oral endotracheal tube. ${ }^{6-9}$ However, the role of tracheostomy in mechanically 
ventilated patients with COVID-19 remains controversial. Guidance at the start of the pandemic, based largely on expert opinion, recommended avoiding or delaying tracheostomy until 14-21 days after intubation, ${ }^{10-12}$ and to only proceed once the patient was COVID-19 reverse transcription (RT)-PCR test negative. ${ }^{13-15}$ These measures aimed to prevent nosocomial infection among healthcare professionals and to avoid futile procedures in ventilated patients with COVID-19 who were predicted not to survive or benefit from the procedure. ${ }^{16} 17$ These recommendations have since been challenged as the risk of transmission is now known to decline shortly after symptom onset and the outcome of COVID-19 testing is believed not to correlate with risk of infectivity later in the disease process. ${ }^{18} 19$ COVIDTrach is a UK multidisciplinary collaborative project that was established to provide an evidence base for the role of tracheostomy in mechanically ventilated patients with COVID-19 in intensive care units (ICUs) and to assess the occurrence of SARS-CoV-2 infection among operators. An interim report documenting the first 548 patients during the first 2 months of the pandemic reported a hospital mortality of $12 \%$, weaning success in $52 \%$ and no instances of SARS-CoV-2 infection among operators at the time of writing. ${ }^{20}$ This article presents a larger cohort of 1605 patients and links clinical parameters to patient outcomes using regression analysis and predictive modelling.

\section{METHODS}

\section{Study design}

An invitation for clinicians to participate in the COVIDTrach project was disseminated via the UK Federation of Surgical Specialty Associations, its various member organisations and the Intensive Care Society to reach all UK departments involved in tracheostomy in patients with COVID-19. Inclusion into the study was also advertised on societal websites and social media. Overall, 137 hospital sites agreed to participate across all four nations of the UK.

\section{Patient population}

Each participating hospital included all consecutive adult patients over 18 years of age with COVID-19 who underwent elective tracheostomy while receiving invasive mechanical ventilation. Infection was identified by a positive viral RNA test on quantitative RT-PCR testing or when strongly suspected on history, laboratory and radiological findings in the absence of viral RNA test availability or a positive result. Patients under the age of 18 years and those undergoing emergency tracheostomy were excluded.

\section{Clinical indicators and outcome measures}

Demographic data, clinical characteristics, SARS-CoV-2 status, ventilatory requirements before tracheostomy, details of the tracheostomy and the use of personal protective equipment (PPE) were all recorded (data dictionary in online supplemental appendix). Clinical outcomes included complications, mortality, time from tracheostomy to weaning from mechanical ventilation, success, and time to tracheostomy decannulation, and time from tracheostomy to hospital discharge. Successful weaning was defined as being free from pressure support for greater than 24 hours. Participants were also asked to report whether any of the operators performing the procedure tested positive for SARS-CoV-2 within 2 weeks of the procedure.

\section{Procedures}

Data were collected using an online survey tool (REDCap) with return codes issued to allow participants to update clinical outcomes prospectively. All participants were asked to update the clinical outcomes of their cases by 1 July 2020 and confirm the data were complete. Hospital sites with missing data or data were followed up over the course of July and early August. Hospitals with datasets not updated by 15 August 2020 were removed from the study $(\mathrm{n}=11)$.

\section{Data governance}

All data collected were anonymised and non-identifiable and did not alter the patient's clinical care. Participant consent was not sought as per the UK Control Of Patient Information (COPI) notice (Department of Health and Social Care, 2020).

\section{Statistical analysis}

Variables are presented using either mean (SD), median (IQR) or number (percentage), as appropriate. Groups of variables were compared using either t-tests or $\chi^{2}$ tests, as appropriate. For regression analysis, all numerical variables, except age and body mass index, were log transformed to remove positive skewness. Logistic regression was used to develop a model for mortality, after imputing missing values using multiple imputation via chained equations. ${ }^{21}$ In detail, the imputation model included all potential predictor variables as well as the outcome; 10 imputed datasets were produced. Backwards elimination at the $15.7 \%$ significance level was used to remove unimportant variables from the model. This model was internally validated using tenfold cross-validation. Model performance (calibration and discrimination) was assessed using the calibration slope and calibration in the large, and receiver operating characteristic (ROC) curves. Multiple regression was used to develop a model for $(\log )$ time to wean success, since we only had information on those for whom wean was successful and hence there was no censoring. Backward elimination was again applied at the $15.7 \%$ significance level.

\section{RESULTS}

Participants

Between 6 April and 26 August 2020, data were received on 1605 tracheostomies from 126 UK hospitals led by a 
combination of ENT, maxillofacial and intensive care specialists. The number of tracheostomy cases entered by each hospital ranged from 1 to 106 (mean 12, SD 15.2). Across all cases, over $90 \%$ of all data points were completed in all but three variables where completeness was $85 \%$ or greater (online supplemental table 1). The average patient age was $58 \pm 11$ years, with a $70: 30$ maleto-female ratio. More detailed patient demographics and medical history are presented in table 1 and COVID-19 test status in table 2 .

\section{Tracheostomy procedure}

The median time from intubation to tracheostomy was 15 days (IQR 11, 21) (figure 1A). Overall, $73(4.5 \%)$ patients had tracheostomy within 4 days of intubation and 227 (14\%) after 25 days. The mean C reactive protein (CRP) on the day of tracheostomy was $119(\mathrm{SD}, 88) \mathrm{mg} / \mathrm{L}$.

'Anticipated prolonged wean' was the most cited indication for tracheostomy in 1473 (92\%). An open method of tracheostomy was used in $797(50 \%)$ procedures, percutaneous method in $771(48 \%)$ and a hybrid method using a combination of open and percutaneous techniques in 31 (2\%) (figure 1B). Bronchoscopy was used as an aid in $574(78 \%)$ percutaneous techniques. Patient factors likely to make the tracheostomy more challenging were reported in $327(41 \%)$ open and 109 (14\%) percutaneous tracheostomies. Of these, neck obesity was the most frequently reported, occurring in $242(30 \%)$ of all open tracheostomies.

Operators used either a mask with FFP3 level filtration or powered air-purifying respirator (PAPR) in 1563 $(99 \%)$ of cases (figure 2C). Other PPE included double gloves in $1460(91 \%)$, a surgical gown in $1511(94 \%)$ and a face visor was used in $1261(96 \%)$ of cases in addition to an FFP3 mask.

\section{Complications}

Intraoperative complications were reported in 147 (9\%) procedures with oxygen desaturation below $80 \%$ being the most common $(n=67)$, followed by intraoperative bleeding $(\mathrm{n}=29)$. Postoperative complications occurred in $356(22 \%)$ cases; bleeding was reported in $119(7 \%)$ patients, more frequently following open procedures $(\mathrm{p}<0.001)$. A leak around the tracheostomy cuff necessitating a change in tube was reported in $75(5 \%)$ cases, 48 of these were open tracheostomies.

\section{Outcomes}

One patient died during the tracheostomy procedure, two hundred and seventy-six (17\%) patients died before weaning from mechanical ventilation and a further nine $(1 \%)$ patients died between successful weaning and hospital discharge (table 3). Overall, 249 (89\%) deaths were COVID-19 related and nine patients died of tracheostomy-related complications. The median time from tracheostomy to death was 9 days (IQR 5, 14).

Characteristics of survivors and non-survivors are shown in online supplemental table 2. A multivariable logistic
Table 1 Patient demographics and medical history of 1605 mechanically ventilated patients with COVID-19 who underwent tracheostomy

\begin{tabular}{|c|c|}
\hline Demographics & $\begin{array}{l}\text { Patients with } \\
\text { COVID-19 undergoing } \\
\text { tracheostomy }\end{array}$ \\
\hline \multicolumn{2}{|l|}{ Age (years) $(\mathrm{N}=1605)$} \\
\hline Mean (SD) & $58(11)$ \\
\hline \multicolumn{2}{|l|}{$\operatorname{Sex} n(\%)(N=1605)$} \\
\hline Male & $1122(70)$ \\
\hline Female & $482(30)$ \\
\hline \multicolumn{2}{|l|}{ Body mass index $\mathrm{n}(\%)$} \\
\hline$<18.5$ & $13(<1)$ \\
\hline $18.5-24.9$ & $355(25)$ \\
\hline $25-29.9$ & $478(33)$ \\
\hline $30-39.9$ & $468(33)$ \\
\hline$\geq 40$ & $122(8)$ \\
\hline \multicolumn{2}{|l|}{$(\mathrm{N}=1437 / 1605)$} \\
\hline \multicolumn{2}{|l|}{ Medical history } \\
\hline $\begin{array}{l}\text { Time from admission to hospital to intubation, } \\
\text { median (IQR)(N=1518/1606) }\end{array}$ & $2(0,4)$ \\
\hline $\begin{array}{l}\text { Use of NIV between admission to hospital and } \\
\text { intubation } n(\%)(N=1525 / 1605)\end{array}$ & $651(43)$ \\
\hline $\begin{array}{l}\text { Time from intubation to tracheostomy in days, } \\
\text { median (IQR)(N=1565/1605) }\end{array}$ & $15(11,21)$ \\
\hline \multicolumn{2}{|l|}{ Relevant comorbidities n (\%) } \\
\hline None & $391(24)$ \\
\hline 1 & $563(35)$ \\
\hline 2 & $412(26)$ \\
\hline 3 & $120(7)$ \\
\hline$>3$ & $36(2)$ \\
\hline \multicolumn{2}{|l|}{$(n=1521 / 1605)$} \\
\hline \multicolumn{2}{|l|}{ Temperature at tracheostomy $>37.5^{\circ} \mathrm{C}, \mathrm{n}(\%)$} \\
\hline Day of tracheostomy & $377(23)$ \\
\hline $1-2$ days before & $403(25)$ \\
\hline $3-4$ days before & $250(16)$ \\
\hline 5 days before & $451(28)$ \\
\hline \multicolumn{2}{|l|}{$(\mathrm{N}=1481 / 1605)$} \\
\hline \multicolumn{2}{|l|}{ CRP at the time of tracheostomy } \\
\hline CRP downtrending & $1070(68 \%)$ \\
\hline Mean CRP (SD) & $119(88)$ \\
\hline Median CRP (IQR) & $100(50,165)$ \\
\hline \multicolumn{2}{|l|}{$(\mathrm{N}=1583 / 1605)$} \\
\hline Inotropic support at the time of tracheostomy, n (\%) & $606(39)$ \\
\hline \multicolumn{2}{|l|}{$(\mathrm{N}=1565 / 1605)$} \\
\hline \multicolumn{2}{|c|}{ Ventilatory requirements on the day of tracheostomy, median (IQR) } \\
\hline $\mathrm{FiO}_{2}(\%)(\mathrm{N}=1549 / 1605)$ & $40(30,45)$ \\
\hline $\mathrm{PaO}_{2}(\mathrm{kPa})(\mathrm{N}=1549 / 1605)$ & $9.8(9,11)$ \\
\hline $\operatorname{PEEP}\left(\mathrm{cmH}_{2} \mathrm{O}\right)(\mathrm{N}=1533 / 1605)$ & $8(6,10)$ \\
\hline $\mathrm{PaO}_{2} / \mathrm{FiO}_{2}$ ratio & $195(153,248)$ \\
\hline
\end{tabular}

$\mathrm{N}$ represents the number of survey responses over the total number of possible responses as an indicator of data completeness (see also online supplemental table 1). $\mathrm{CRP}, \mathrm{C}$ reactive protein; $\mathrm{FiO}_{2}$, inspired oxygen concentration; NIV, non-invasive ventilation; $\mathrm{PaO}_{2}$, arterial oxygen tension. 
Table 2 The outcome of COVID-19 PCR testing in 1605 mechanically ventilated patients with COVID-19 undergoing tracheostomy

\begin{tabular}{|c|c|}
\hline COVID-19 PCR test in patients undergoing tra & cheostomy \\
\hline Test positive during admission to hospital $\mathrm{n}(\%)$ & \\
\hline Positive & $1473(92)$ \\
\hline Negative & $126(8)$ \\
\hline Total number of tests during admission to hospit & \\
\hline Median (IQR) & $1(1,2)$ \\
\hline Outcome of last test before tracheostomy $\mathrm{n}(\%)$ & \\
\hline Positive & $1213(83)$ \\
\hline Negative & $242(17)$ \\
\hline Outcome of second to last test before tracheostc & omy n (\%) \\
\hline Positive & $678(75)$ \\
\hline Negative & $228(25)$ \\
\hline $\begin{array}{l}\text { Number of cases with two negative tests before } \\
\text { tracheostomy } n(\%)\end{array}$ & $115(7)$ \\
\hline Number of days from last test to tracheostomy & \\
\hline Median (IQR) & $12(6,18)$ \\
\hline
\end{tabular}

regression model was fitted for mortality and backward elimination applied. Age, days of mechanical ventilation preprocedure, inspired oxygen concentration and positive end-expiratory pressure (PEEP) setting at the time of tracheostomy, use of inotropic support (all $\mathrm{p}<0.001$ ), upward trending CRP $(\mathrm{p}=0.003)$, fever $(\mathrm{p}=0.003)$ and use of anticoagulation $(\mathrm{p}=0.002)$ are independently associated with mortality (figure $2 \mathrm{~A}$ ).

Internal validation using tenfold cross-validation produced an average ROC area of 0.75 (range: 0.640.87 ), suggesting good discrimination (figure 2B). The Hosmer-Lemeshow test results in each cross-validation fold suggest no problems with calibration. A comparison of observed and predicted outcomes suggests good agreement (figure 2C).

Of the survivors, 1229 (93\%) had been successfully weaned at the time of analysis with 1154 (88\%) having undergone successful tube decannulation and 1049 $(81 \%)$ discharged from hospital (table 3). Median time from tracheostomy to discharge from hospital in survivors was 29 days (IQR 21, 42).

Characteristics of surviving patients according to length of time to successful wean from ventilation are shown in online supplemental table 3. A multiple regression model for time to wean success was fitted and backward elimination applied. These results suggest that advanced age, male sex, higher PEEP setting, higher inspired oxygen requirement, use of anticoagulation (all $\mathrm{p}<0.001)$ and non-invasive ventilation before tracheostomy $(\mathrm{p}=0.003)$ were all independently associated with prolonged periods of ventilation following tracheostomy among those for whom wean was successful (figure 2D). An association was found between insertion technique and time to successful wean, although the difference was small (median 12 days for percutaneous vs 11 days
A

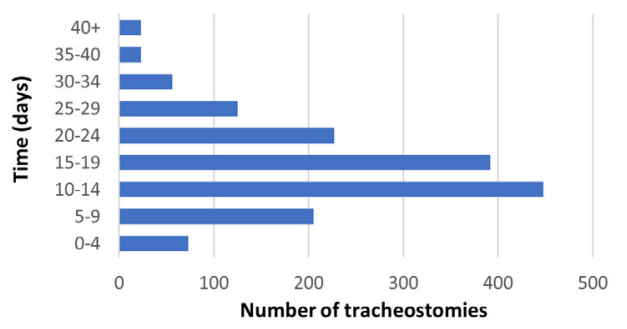

B

घNT $\square$ OMFS $\square$ Thoracics $\square$ General Surgery $\square$ ICU $\square$ Other

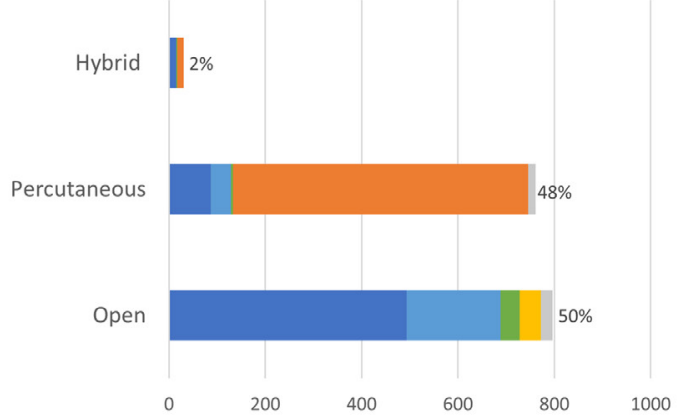

C

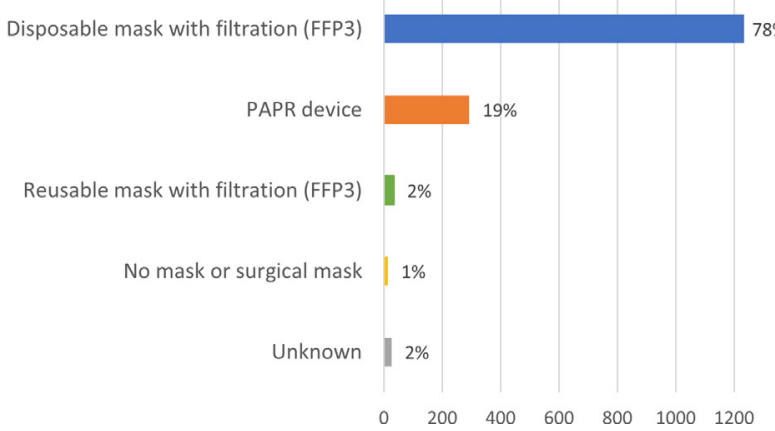

Figure 1 (A) Length of time from intubation to tracheostomy (days). (B) Number of tracheostomies divided by method and specialist performing the procedure. (C) Type of respirator used during the tracheostomy, $x$ axis=total number of cases using that type of respirator. PARP; powered air-purifying respirator.

for open method). No association was found between time from intubation to tracheostomy and time from tracheostomy to successful ventilatory wean $(\mathrm{p}=0.92)$.

\section{SARS-CoV-2 infection in operators}

The question 'Did any of the operators test positive for COVID-19 within 2weeks of the procedure?' was answered in $97 \%(1558 / 1605)$ of cases. Six instances were reported across four hospitals, four after percutaneous tracheostomy and two after open tracheostomy. Five of the cases were performed in intensive care and four within a negative pressure environment. PPE used in these cases included an FFP3 mask in four cases, a fluid-resistant hood with face visor in one, and a PAPR device in one.

\section{DISCUSSION}

This study involved 126 UK hospitals reporting on 1605 individual tracheostomies between March and August 2020. 


\begin{tabular}{|c|c|c|c|}
\hline A & Category & OR (95\% Cl) & P-value \\
\hline Predictor & & $1.043(1.028$ to 1.059$)$ & $<0.001$ \\
\hline FiO2 & $<30$ & 1 & \\
& $30-39$ & $2.31(1.09$ to 4.88$)$ & 0.028 \\
& $40-49$ & $4.36(2.10$ to 9.06$)$ & $<0.001$ \\
& $50+$ & $6.80(3.23$ to 14.30$)$ & $<0.001$ \\
\hline PEEP setting & $<6$ & 1 & \\
& $6-7.9$ & $1.54(0.80$ to 2.95$)$ & 0.192 \\
& $9-9.9$ & $2.22(1.30$ to 3.78$)$ & 0.004 \\
& $10+$ & $3.05(1.81$ to 5.16$)$ & $<0.001$ \\
\hline Days of ventilation before tracheostomy & $<=7$ & 1 & \\
& $8-12$ & $0.57(0.35$ to 0.92$)$ & 0.022 \\
& $>12$ & $0.43(0.28$ to 0.67$)$ & $<0.001$ \\
\hline Pyrexia & day of tracheostomy & 1 & \\
& $1-2$ days before & $0.87(0.56$ to 1.34$)$ & 0.521 \\
& $3-4$ days before & $1.32(0.82$ to 2.12$)$ & 0.251 \\
& $5+$ days before & $1.55(1.04$ to 2.30$)$ & 0.030 \\
\hline Downward CRP & & $0.59(0.44$ to 0.80$)$ & 0.001 \\
\hline Therapeutic Anticoagulation & & $1.64(1.22$ to 2.20$)$ & 0.001 \\
\hline Inotropic Support & & $1.78(1.33$ to 2.39$)$ & $<0.001$ \\
\hline
\end{tabular}
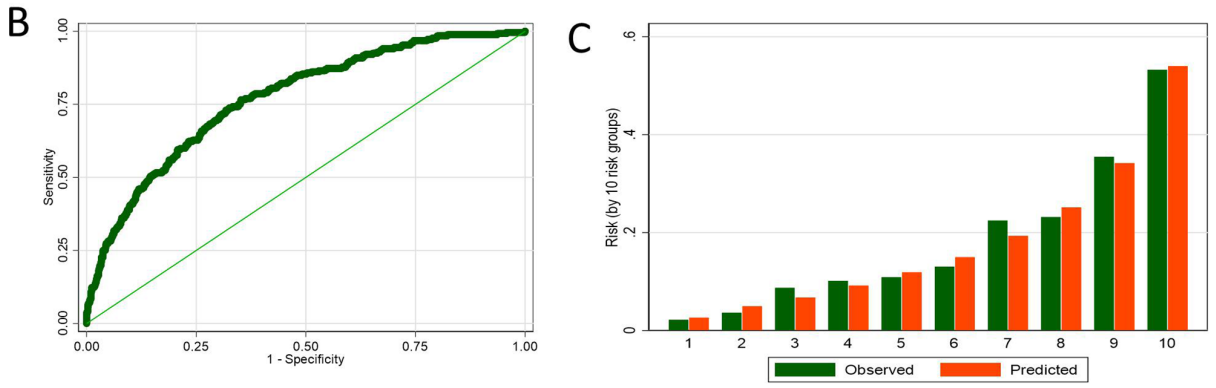

\begin{tabular}{|c|c|c|c|}
\hline Predictor & Category & Coefficient (95\% Cl) & P-value \\
\hline Age (years) & & $0.010(0.006$ to 0.014$)$ & $<0.001$ \\
\hline Sex & Female & $-0.099(-0.188$ to -0.011$)$ & 0.028 \\
\hline FiO2 & $<30$ & - & \\
& $30-39$ & $0.109(-0.018$ to 0.235$)$ & 0.092 \\
& $40-49$ & $0.190(0.057$ to 0.323$)$ & 0.005 \\
& $50+$ & $0.347(0.196$ to 0.498$)$ & $<0.001$ \\
\hline PEEP setting & $<6$ & - & \\
& $6-7.9$ & $0.039(-0.094$ to 0.173$)$ & 0.561 \\
& $8-9.9$ & $0.157(0.042$ to 0.272$)$ & 0.007 \\
& $10+$ & $0.219(0.097$ to 0.340$)$ & $<0.001$ \\
\hline Method of tracheostomy & Percutaneous & $0.101(0.017$ to 0.185$)$ & 0.018 \\
\hline Anticoagulant & Yes & $0.151(0.068$ to 0.235$)$ & $<0.001$ \\
\hline Use of NIV & Yes & $0.123(0.039$ to 0.206$)$ & 0.004 \\
\hline Inotropic support & Yes & $0.092(0.005$ to 0.178$)$ & 0.038 \\
\hline
\end{tabular}

Figure 2 (A) ORs from multivariable logistic regression model for mortality $(n=1566)$. Eight predictive clinical variables were identified. Days of ventilation, $\mathrm{FiO}_{2}$ and PEEP setting are presented using categories to aid interpretation. (B) ROC curve for multivariable prediction model. Internal validation using tenfold cross-validation produced an average ROC area of 0.75 (range: $0.64-0.87$ ). (C) Observed and predicted risk for 10 quantile groups. The groups (1-10) were obtained by splitting patients by their predicted risk, that is, group 1 comprise the $10 \%$ of patients with the lowest predicted risk. (D). Regression coefficients from multiple regression model for time to wean success $(n=1031)$. CRP, $C$ reactive protein; $\mathrm{FiO}_{2}$, inspired oxygen concentration; NIV, non-invasive ventilation.

During this same period, 7792 patients were recorded by the UK's Intensive Care National Audit \& Research Centre (ICNARC) as receiving advanced respiratory support in England, Wales and Northern Island. ${ }^{22}$ Gender ratio, mean age and body mass index grouping are all comparable between the COVIDTrach database and the ICNARC database indicating our cohort is representative, and the results are likely generalisable to the UK.

At the time of censoring, all-cause mortality following tracheostomy in our cohort was $18 \%$. This number is likely to rise as 91 patients were still mechanically ventilated and a further 171 had been weaned but were still in hospital. Prospective multicentre studies of general (non-COVID-19) intensive care populations patients report mortality rates of approximately $30 \%$ in the first 30 days following tracheostomy. ${ }^{23}{ }^{24}$ Direct comparisons to this cohort of patients with COVID-19 cannot, however, be drawn as demographics, comorbidities and underlying pathologies will differ considerably and timing of tracheostomy is usually performed earlier than the median 15 
Table 3 Outcomes of mechanically ventilated patients with COVID-19 undergoing tracheostomy

\section{Outcomes following tracheostomy in patients with COVID-19}

\begin{tabular}{|c|c|}
\hline $\begin{array}{l}\text { All cause mortality following tracheostomy in } \\
\text { COVID-19, } n(\%)\end{array}$ & atients with \\
\hline Died during tracheostomy & $1(<1)$ \\
\hline $\begin{array}{l}\text { Died before successful wean from } \\
\text { mechanical ventilation }\end{array}$ & $276(17)$ \\
\hline $\begin{array}{l}\text { Died between wean from ventilation and } \\
\text { discharge from hospital }\end{array}$ & $9(1)$ \\
\hline Cause of death following tracheostomy, $\mathrm{n}(\%)$ & \\
\hline COVID-19 related & $249(89)$ \\
\hline Tracheostomy related & $9(3)$ \\
\hline Other & $22(8)$ \\
\hline Weaning from mechanical ventilation in survivc & rs, n (\%) \\
\hline $\begin{array}{l}\text { Successfully weaned from mechanical } \\
\text { ventilation }\end{array}$ & $1229(93)$ \\
\hline Still ventilated at the time of analysis & $91(7)$ \\
\hline $\begin{array}{l}\text { Time (days) from tracheostomy to successful } \\
\text { wean, median (IQR) }\end{array}$ & $11(7,18)$ \\
\hline $\begin{array}{l}\text { Total length (days) of critical care in survivors, } \\
\text { median (IQR) }\end{array}$ & $33(25,44)$ \\
\hline $\begin{array}{l}\text { Total length (days) of critical care in non- } \\
\text { survivors, median (IQR) }(\mathrm{N}=264)\end{array}$ & $23(16,32)$ \\
\hline $\begin{array}{l}\text { Successful tracheostomy decannulation at } \\
\text { analysis, } \mathrm{n}(\%)\end{array}$ & $1154(88)$ \\
\hline Discharge from hospital, n (\%) & $1049(81)$ \\
\hline $\begin{array}{l}\text { Time (days) from tracheostomy to discharge } \\
\text { from hospital in survivors, median (IQR) }\end{array}$ & $29(21,42)$ \\
\hline
\end{tabular}

days following intubation reported in this study of patients with COVID-19. National data, reported in the ICNARC registry, indicate that the ICU mortality rate in mechanically ventilated patients with COVID-19 was $47.8 \%$; however, median duration of critical care stay in nonsurvivors was 10 days (IQR 6, 17). ${ }^{22}$ Given median time to tracheostomy in our cohort was 15 days, patients with COVID-19 undergoing tracheostomy constitute a preselected population who have survived the acute phase and, in general, would have cardiorespiratory stability and are no longer requiring high-level ventilatory support and high-inspired oxygen concentrations. Nonetheless, our data show that tracheostomy in the setting of SARS-CoV-2 infection is not a futile intervention as previously claimed by expert opinion at the start of the pandemic. ${ }^{16} 17$

Whether the timing of tracheostomy does influence patient with COVID-19 outcomes is unclear. Early tracheostomy may benefit certain patient groups, ${ }^{25}{ }^{26}$ but metaanalyses have failed to show benefit in a general population of critically ill adults. ${ }^{27}$ In our cohort, early tracheostomy was independently associated with higher mortality. Moreover, no association was demonstrated between early tracheostomy and shortened time to successful weaning from ventilation. Cause and effect cannot be directly inferred from these data and only prospective randomised studies could address this important question.

We found no association between method of tracheostomy and likelihood of successful wean from ventilation, mortality, or discharge from hospital. As in non-COVID-19 series, bleeding was more frequent using the open method, although the overall rate of reported bleeding was low. The percutaneous method has several advantages centred around the ability to perform the procedure at the bedside. In contrast, the open method enables safe procedure in those with difficult neck anatomy and enables the surgical workforce to relieve the task from intensive care staff during periods when a critical care department is working at full capacity. The decision over which method to employ should be locally led and depends on expertise available and close interdisciplinary working.

The low rates of reported SARS-COV-2 infection among operators who likely continued to work in other high-risk areas and performed other aerosol generating procedures are encouraging. While asymptomatic cases may have been missed and recall bias may have occurred, the low rates of infection suggest that, with appropriate PPE, the procedure does not pose a high risk of infection with SARS-COV-2 to operators. Our findings are consistent with other series. ${ }^{29} 30$

Infectivity and viral load is believed to peak around the time of symptom onset and then decline over the following 3-4 days. ${ }^{31} 32$ Considering the median time from symptom presentation to hospitalisation is 4 days and that tracheostomy is not usually considered until at least 7 days after intubation, the risk of infectivity is predicted to be low even if the procedure is performed between the first and second week of ventilation. ${ }^{33}$ Our results, therefore, do not support guidance suggesting tracheostomy should be delayed until 14-21 days after intubation to reduce the potential for infection among operators. ${ }^{12} 14$ Similarly, our findings and data showing a positive COVID-19 test does not correlate with risk of infectivity later in the disease process, suggest tracheostomy should not be delayed to achieve a negative COVID-19 test. Delaying in these circumstances defers the potential benefits of tracheostomy and increases the risk of complications relating to prolonged endotracheal intubation without any clear benefit to the patient or operators involved in the procedure.

Collaborators NJI Hamilton; AGM Schilder; T Jacob; G Ambler; M Singer; MM George; F Green; GM Jama; J Goulder; E Jackson; A Arora; N Kumar; C Schilling; S Laha; I Ahmad; B McGrath; MA Birchall; NS Tolley; G Sandhu; T Tatla; N Sharma; P Stimpson; P Andrews; N Mercer; P Nankivell; 0 Breik; P Praveen; M Idle; T Martin; S Parmar; P Pracy; C Jennings; J Higginson; K Fan; E Yeung; J Osher; R Bentley; C Huppa; P Stenhouse; K Hussain; S Hodges; F Ryba; P Surda; EK Bhargava; N Amin; J Collins; M Kelly; D Ranford; A Takhar; C Tornari; M Verkerk; C Xie; D Pennell; C Al-Yaghchi; L Ritchie; M Jaafar; M Rouhani; M Ashcroft; N Cereceda-Monteoliva; A Holroyd; J Ng; R Mistry; K Ghufoor; E Warner; H O'Mahony; S Shepherd; N Bhatti; H Drewery; J Hadley; A Mulcahy; H Wilson; R Bhandari; M Griffiths; T Magos; I Balasundaram; M Heliotis; A Loizidou; D York; R Exley; KA Solanki; P Shah; P Kirticumar; A Shah; S Shannon; A Shirazian; Y Bhatt; R Natt; C Spencer; 
R D'Souza; N Banga; D Baker; K Dhadwal; Z Abdi; T Exall; I Ekpemi; R RoplekarBance; C Walker; N Glibbery; K Karamali; A Li; A Rovira; D Dawson; T MunroeGray; P Sethukumar; R Vasanthan; J Phillips; A Williamson; R Saha; M Roberts; H Lee-Six; B Misztal; S Millington; M Musalia; S Suresh; A Cardozo; M Dunbobbin; A Tse; S Shahidi; M Chachlani; K Jolly; J Fussey; M Misurati; M Osborne; S Ashok; H Aboulgheit ; S Khwaja; R Anmolsingh; C Smyth; B Al-Dulaimy; E Omakobia; J Collier; T Browning; A Courtney; P Ward; L Lignos; C Lockie; P Twose; J Heyman; S Berry; P Bishop; D Kathwadia; T Hwara; A Williamson; A Kumar; 0 Judd; W Parker; TP Davis; T Stubington; T Ali; A Schache; H Koumoullis; E Willcocks; L Skeely; G Dempsey; K Liatsikos ; B Borgatta; J Rodrigues; A Glossop; J Sen; N Lawrence; S Bennett; L Wren; V Politidis; D Dhariwal; S Winter; A Kara; T Hunt; G Tattersall; W Udall; B Hill; S Saha; L Bates; C Smart; D Park; R O'Brien; L Linhartova; P Kirkland; J Staufenberg; K Valchanov; H Buglass; U Sheikh; E Tam; J Williamson; A McGrath; S Siddiq; NW Wahid; H Griffiths; M De; A Amlani; P Deutsch; K Markham; C Hall; S Webster; 0 Barker; P Sykes; A Gupta; A Easthope; S Glaze; B Morris; D Bondin; D Thorley; K Kapoor; S Sirajuddin; S Fang; F van Damme; 0 Mattoo; E Paramasivam; E Kershaw; S Dewhurst; S Blakeley; C Chivers; L Lindsey; DJ Lin; A Burns; A Wilson; N Macartney; F Franco; K Goodwin; B Cosway; R Glore; H Cunniffe; M Keil ; S Burrows; D Moult; D Zolger; J Bakmanidis; D Nair; S Kandiah; M Anwar; A Pericleous; C Hogan; R Temple; D Whitmore; R Sheikh; R Pinto; C Cook; J Broad; U Nagalotimath; E El-Tabal; S Ghaffar; M Dallison; E Leakey; R Harris; J Blair; E France; 0 Sanders; P Mukherjee; A Gomati; L Moir ; CB Groba; C Davies-Husband; N Seymour; S Mahalingam; D Williams; R Lovett; J Lunn; A Armson; A Balfour; K Steele; K Hilliard; S Ladan; P Paul; P Tsirevelou; V Ratnam; H Turner; N Jain; A Muddaiah; M Celinski; J Smith; J Westwood; J Coakes; R Borg; J McEwan; A Tsagkovits; 0 Mulla; N Stobbs; G Warner; D Pratap; Z Ghani; J Rocke; S Snape; S Ghosh; A Hassaan; M Cameron; A Daudia; S Menon; S Beckett; R Siau; A Howard ; C Lamont; C Blore; C Pearce; D Zakai; S Biswas; R Moorthy; J Bates; P Gill; E Riley; P Bothma; S Meghji; W Rutherford; A Lloyd; A Syndercombe; P Smith; N Keates; V Srinivasan; M Junaid; M Kumar; T Antonio ; A Vijendren; V Venkatachalam; I Gonzalez; M Lechner; D Chandrasekharan; A Arya; R Brown; H Jones; D Kumar; R Sykes; B Tehan; A Walker; J Whiteside; F Cooper; A Coombs; G Wong; D Walker; S Dennis; A Hormis; A Eldahshan; L Leach; H Paw; M Colomo-Gonzalez; D Chakravarty; S Sanyal; N Mani; B Ranganathan; H Saeed; S Linton; A Thompson; J Whittaker; N Amiruddin; A Sladkowsk; R Gohil; AK Abou-Foul; J Ahmed; S Kishwan; G Walton; P Naredla; A Al-Ajami; S Wilkinson; S Okhovat; A Menon; S Mustafa; E Carey; N Vallabh; T Davies; A. Alatsatianos; R Townsley.

Contributors NH contributed to literature search, figures, study design, data collection, analysis, interpretation and writing. AS contributed to study design, data analysis and interpretation and writing. GA contributed to data analysis, interpretation and writing. TJ and AA contributed to study design, data interpretation and writing. MS contributed to data analysis and interpretation and writing. MG, FG, GJ, JG and EJ contributed to figures, data analysis and editing. All other authors contributed equally under the principles of corporate authorship.

Funding The COVIDTrach project is supported by the Wellcome Trust UCL COVID-19 Rapid Response Award and the National Institute for Health Research (NIHR). COVIDTrach is supported by the Wellcome Trust University College London COVID-19 Rapid Response award (BRC732/JK/101400) and the NIHR Clinical Research Network. NH is an NIHR Clinical lecturer and is supported by the Royal College of Surgeons (RCSEng) and the Academy of Medical Sciences (SGL021 1046). AGMS is an NIHR senior investigator and director of the NIHR UCLH BRC Hearing Theme; the research of her UCL Ear Institute evidENT team is supported by the NIHR (Biomedical Research Centre, Applied Research Collaboration, Clinical Research Network, Programme Grants for Applied Research, Research for Patient Benefit), Wellcome Trust, RCSEng, and EU Horizon2020. MB is an NIHR senior investigator. Data collection through British Association of Oral Maxillofacial Surgeons was managed by Fabien Puglia and supported by NFORC and Saving faces.

Competing interests None declared.

Patient consent for publication Not required.

Ethics approval COVIDTrach has been approved by the UK Research and Ethics Council and the Health Research Authority (20/HRA/3766) as a prospective cohort study, the Scottish Public Benefit and Privacy Panel and Northern Island's Privacy Advisory Committee and was registered as a service evaluation or research study at each participating site.

Provenance and peer review Not commissioned; externally peer reviewed.

Data availability statement All data relevant to the study are included in the article or uploaded as supplementary information. Data are included in the supplementary materials.
Open access This is an open access article distributed in accordance with the Creative Commons Attribution Non Commercial (CC BY-NC 4.0) license, which permits others to distribute, remix, adapt, build upon this work non-commercially, and license their derivative works on different terms, provided the original work is properly cited, appropriate credit is given, any changes made indicated, and the use is non-commercial. See: http://creativecommons.org/licenses/by-nc/4.0/.

\section{REFERENCES}

1 Wu Z, McGoogan JM. Characteristics of and Important Lessons From the Coronavirus Disease 2019 (COVID-19) Outbreak in China: Summary of a Report of 72314 Cases From the Chinese Center for Disease Control and Prevention. JAMA 2020;323:1239-42.

2 Grasselli G, Pesenti A, Cecconi M. Critical care utilization for the COVID-19 outbreak in Lombardy, Italy: early experience and forecast during an emergency response. JAMA 2020;323:1545-6.

3 Cummings MJ, Baldwin MR, Abrams D, et al. Epidemiology, clinical course, and outcomes of critically ill adults with COVID-19 in New York City: a prospective cohort study. Lancet 2020;395:1763-70.

4 Grasselli G, Zangrillo A, Zanella A, et al. Baseline characteristics and outcomes of 1591 patients infected with SARS-CoV-2 admitted to ICUs of the Lombardy region, Italy. JAMA 2020;323:1574-81.

5 Suleyman G, Fadel RA, Malette KM, et al. Clinical characteristics and morbidity associated with coronavirus disease 2019 in a series of patients in metropolitan Detroit. JAMA Netw Open 2020;3:e2012270.

6 Durbin CG, Perkins MP, Moores LK. Should tracheostomy be performed as early as 72 hours in patients requiring prolonged mechanical ventilation? Respir Care 2010;55:76-87.

7 Groves DS, Durbin CG. Tracheostomy in the critically ill: indications, timing and techniques. Curr Opin Crit Care 2007;13:90-7.

8 Jaeger JM, Littlewood KA, Durbin CG. The role of tracheostomy in weaning from mechanical ventilation. Respir Care 2002;47:469-80.

9 Pierson DJ. Tracheostomy and weaning. Respir Care 2005;50:526-33.

10 Miles BA, Schiff B, Ganly I, et al. Tracheostomy during SARS-CoV-2 pandemic: recommendations from the new York head and neck Society. Head Neck 2020;42:1282-90.

11 ENT.UK. COVID-19 tracheostomy guidance. Available: https://www. entuk.org/covid-19-tracheostomy-guidance-t-jacob-et-al [Accessed 11 Apr 2020]

12 Sommer DD, Engels PT, Weitzel EK, et al. Recommendations from the CSO-HNS Taskforce on performance of tracheotomy during the COVID-19 pandemic. J Otolaryngol Head Neck Surg 2020;49:23.

13 Association BL. Tracheostomy guideline COVID-19, 2020. Available: https://www.britishlaryngological.org/news/tracheostomy-guidelinecovid-19 [Accessed 05 May 2020].

14 Michetti CP, Burlew CC, Bulger EM, et al. Performing tracheostomy during the Covid-19 pandemic: guidance and recommendations from the critical care and acute care surgery committees of the American association for the surgery of trauma. Trauma Surg Acute Care Open 2020;5:e000482.

15 Heyd CP, Desiato VM, Nguyen SA, et al. Tracheostomy protocols during COVID-19 pandemic. Head Neck 2020;42:1297-302.

16 Lavinsky J, Kosugi EM, Baptistella E, et al. An update on COVID-19 for the otorhinolaryngologist - a Brazilian Association of Otolaryngology and Cervicofacial Surgery (ABORL-CCF) Position Statement. Braz J Otorhinolaryngol 2020;86:273-80.

17 Vukkadala N, Qian ZJ, Holsinger FC, et al. COVID-19 and the otolaryngologist: preliminary evidence-based review. Laryngoscope 2020;130:2537-43.

18 Zou L, Ruan F, Huang M, et al. SARS-CoV-2 viral load in upper respiratory specimens of infected patients. $N$ Engl J Med 2020;382:1177-9.

19 McGrath BA BM, Warrillow SJ, Pandian V, et al. Tracheostomy in the COVID-19 era: global and multidisciplinary guidance. Lancet Resp Med 2020.

20 COVIDTrach collaborative. COVIDTrach; the outcomes of mechanically ventilated COVID-19 patients undergoing tracheostomy in the UK: interim report. Br J Surg 2020;107:e583-e584.

21 van Buuren S, Boshuizen HC, Knook DL. Multiple imputation of missing blood pressure covariates in survival analysis. Stat Med 1999;18:681-94.

22 Centre ICNAR. ICNARC report on COVID-19 in critical care in Egnland, Wales and Northern Ireland 25 September 2020, 2020. Available: https://www.icnarc.org/Our-Audit/Audits/Cmp/Reports [Accessed 28 Sep 2020].

23 Young D, Harrison DA, Cuthbertson BH, et al. Effect of early vs late tracheostomy placement on survival in patients receiving mechanical ventilation: the TracMan randomized trial. JAMA 2013;309:2121-9. 
24 Terragni PP, Antonelli M, Fumagalli R, et al. Early vs late tracheotomy for prevention of pneumonia in mechanically ventilated adult ICU patients: a randomized controlled trial. JAMA 2010;303:1483-9.

25 Wang R, Pan C, Wang X, et al. The impact of tracheotomy timing in critically ill patients undergoing mechanical ventilation: a metaanalysis of randomized controlled clinical trials with trial sequential analysis. Heart Lung 2019;48:46-54.

26 Elkbuli A, Narvel RI, Spano PJ, et al. Early versus Late Tracheostomy: Is There an Outcome Difference? Am Surg 2019;85:370-5.

27 Huang H, Li Y, Ariani F, et al. Timing of tracheostomy in critically ill patients: a meta-analysis. PLoS One 2014;9:e92981.

28 Meng L, Wang C, Li J, et al. Early vs late tracheostomy in critically ill patients: a systematic review and meta-analysis. Clin Respir $J$ 2016;10:684-92.

29 Riestra-Ayora J, Yanes-Diaz J, Penuelas O, et al. Safety and prognosis in percutaneous vs surgical tracheostomy in 27 patients with COVID-19. Otolaryngol Head Neck Surg 2020;163:462-4.
30 Williamson A, Roberts MT, Phillips J, et al. Early percutaneous tracheostomy for patients with COVID-19. Anaesthesia 2021;76:138-9.

31 Wölfel R, Corman VM, Guggemos W, et al. Virological assessment of hospitalized patients with COVID-2019. Nature 2020;581:465-9.

32 McGrath BA, Brenner MJ, Warrillow SJ, et al. Tracheostomy in the COVID-19 era: global and multidisciplinary guidance. Lancet Respir Med 2020;8:717-25.

33 Zhou F, Yu T, Du R, et al. Clinical course and risk factors for mortality of adult inpatients with COVID-19 in Wuhan, China: a retrospective cohort study. Lancet 2020;395:1054-62.

34 Harris PA, Taylor R, Minor BL, et al. The REDCap Consortium: building an international community of software platform partners. $J$ Biomed Inform 2019;95:103208.

35 Harris PA, Taylor R, Thielke R, et al. Research electronic data capture (REDCap)--a metadata-driven methodology and workflow process for providing translational research informatics support. $J$ Biomed Inform 2009;42:377-81. 